\title{
Implementation of Novel Hybrid Solar and Sound Energy System
}

\author{
Reena Garasangi \\ Department of Electrical and Electronics Engineering \\ BLDEA's V.P. Dr.P.G.Halakatti College of Engineering and Technology, \\ Vijayapur-586 103, Karnataka, India \\ Rashmi Pawar \\ Department of Electrical and Electronics Engineering \\ BLDEA's V.P. Dr.P.G.Halakatti College of Engineering and Technology, \\ Vijayapur-586 103, Karnataka, India \\ Vijaykumar Sajjanar \\ Department of Electronics and Communication Engineering, \\ BLDEA's V.P. Dr.P.G.Halakatti College of Engineering and Technology, \\ Vijayapur-586 103, Karnataka, India
}

\begin{abstract}
This paper is to implement hybrid solar and sound energy system for generation of electric energy. Sound and solar are the two different types of renewable energy sources. The main reason to use sound as an input for producing electric energy is, lots of sound is wasted in our surrounding area which can be used as a renewable energy source. And sound energy usage directly contributes in a sound pollution free environment and it helps to overcome shortage of power supply in various fields of life.
\end{abstract}

Keywords-Sound energy; solar energy; piezoelectric transducers; sound pollution; renewable energy

\section{INTRODUCTION}

The law of energy states that "Energy can neither be created nor be destroyed" it can transfer from one form to another. Present research says that by 2030 the non renewable energy sources will be extinguished. Hence nowadays population is concentrating more on new way of producing electric energy by using different kind of renewable energy sources[1]. One of such methods is converting sound energy into electric energy. Piezoelectric transducers play a very vital role in generating electricity from sound in terms of milliwatts and microwatts[2]. This paper explains about implementation of new hybrid panel which is a combination of solarsound panel. The areas like bus-stand, railway station continuous noise energy is present, by using this noise energy electric energy can be generated.

\section{HYBRID SOLAR-SOUND PANEL SETUP}

This project explains about new way of combing solar and sound energy. The hybrid panel consists of two faces the upper face is solar panel and a lower face is sound panel (made up of many numbers of piezoelectric plates) $[1]$.

A. Panel

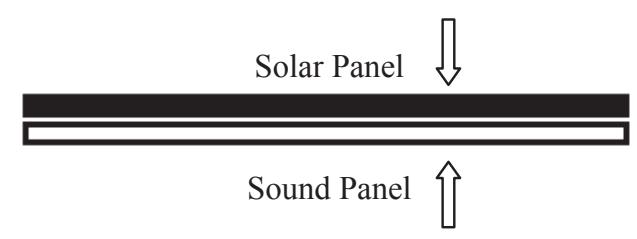

Solar panel is a device which absorbs sunlight as a source of energy for generating electric energy. It consists of number of photovoltaic system connected electrically that generates and supply electric power. The energy generated by the module depends on the area of the module. 
Upper side (Face of Solar Panel)

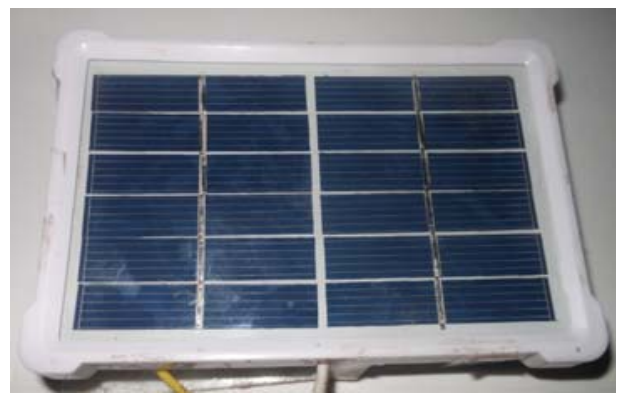

Fig 1: Solar panel (upper face)
Lower side (Face of Sound Panel)

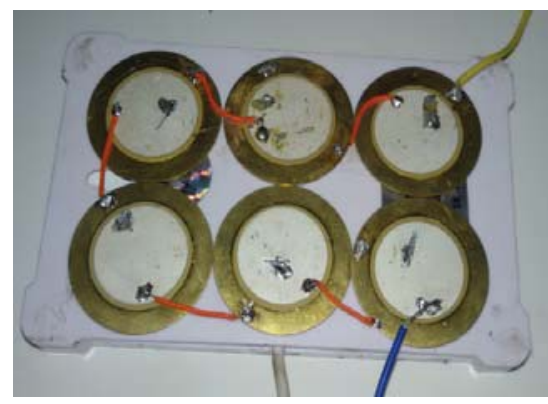

Fig 2: Piezopanel (lower face)

Sound is a mechanical form of energy which travels in the form of wave from one point to other. According to the law of thermodynamics, mechanical energy could be converted into electric energy. The lower face of solar panel is used as sound panel. The sound panel made up of piezoelectric transducers. Piezoelectric transducers are the device which absorbs sound as a source of input for generating electric power.

\section{GENERATION OF ELECTRICITY USING HYBRID SOLAR-SOUND}

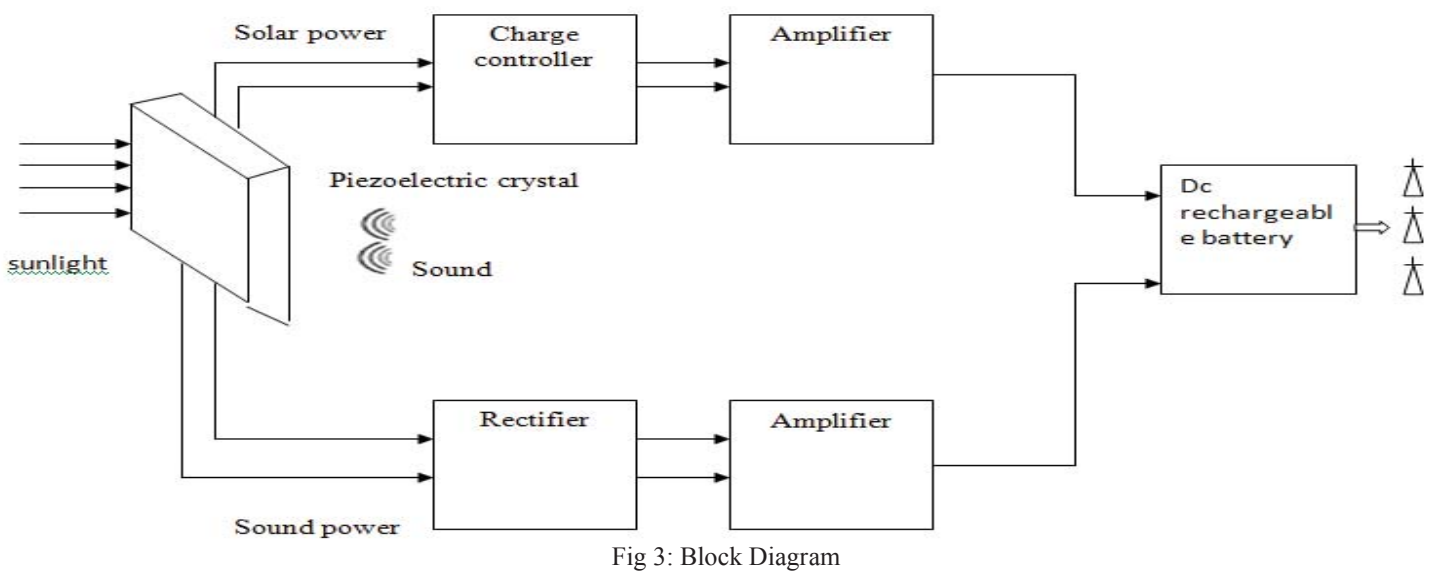

Figure 3 shows the block diagram of the hybrid solar-sound power energy system.

A. Absorption

When sunlight strikes on a solar panel, panel absorbs the solar energy and it converts it into electric power. While the lower face of a solar panel made up of piezoelectric crystal absorb the noise energy from the surrounding medium and it convert noise energy into usable electric energy. [1]

B. Processing

The solar panel produces a dc current but a piezoelectric plates produce ac current. Hence a rectifier is used to convert an alternating current into direct current and it boost up the voltage. The amount of energy we get from the both solar and sound panel is passed through the amplifying circuit to amplify the voltage. The charge controller is used to regulate the voltage and current that storing in a battery.

\section{Combining}

The amount of energy generated by the solar and sound panel is amplified in an amplifier circuit and both energies are combined and supplied to the dc rechargeable battery. The time required to charge a battery is reduced by $50 \%$ because here we are using two energy sources for generating energy and that energy is stored in a battery. 


\section{RESULTS AND DISCUSSION}

The below table shows the readings for solar, sound and hybrid energy system. $1 \mathrm{~W}$ polycrystalline solar panel is used and the readings are noted. 6 piezoelectric plates are connected in series for a particular music for below frequency and $\mathrm{dB}$ voltages are obtained as shown in table.

Table 1: Readings

\begin{tabular}{|c|c|c|c|c|c|c|}
\hline $\begin{array}{c}\text { Sl. } \\
\text { no }\end{array}$ & $\begin{array}{c}\text { Time of } \\
\text { Day }\end{array}$ & $\begin{array}{c}\text { Solar } \\
\text { Panel } \\
\text { Voltage }\end{array}$ & $\begin{array}{c}\text { Frequency } \\
\text { (Sound) }\end{array}$ & $\begin{array}{c}\mathrm{dB} \\
\text { (Sound) }\end{array}$ & $\begin{array}{c}\text { Sound Panel } \\
\text { Voltage }\end{array}$ & $\begin{array}{c}\text { Total Voltage } \\
\text { (volts) }\end{array}$ \\
\hline 1 & Noon & 3.9 & 350 & 65 & 0.15 & 4.05 \\
\hline 2 & Noon & 3.9 & 400 & 65 & 0.22 & 4.12 \\
\hline 3 & Noon & 3.9 & 200 & 65 & 0.16 & 4.06 \\
\hline 4 & Noon & 3.9 & 300 & 65 & 0.45 & 4.35 \\
\hline 5 & Noon & 3.9 & 400 & 70 & 0.32 & 4.22 \\
\hline 6 & Noon & 3.9 & 400 & 68 & 0.36 & 4.26 \\
\hline 7 & Noon & 3.9 & 350 & 65 & 0.21 & 4.11 \\
\hline 8 & Noon & 3.9 & 300 & 70 & 0.06 & 3.96 \\
\hline
\end{tabular}

\section{Calculation}

Power is calculated with this experimental setup. In solar panel $1 \mathrm{~W}$ polycrystalline solar panel consist of 24 solar cell and in sound panel 6 piezoelectric plates are connected in series. The power generated and charging time necessary for various panel sizes are calculated by modeling and simulating in Matlab [3]. Figure 4 shows the relevant simulation graphs for the implemented hybrid solar sound panel.

$$
P=A \times P s \times \eta \times T
$$

where P- Power generated per day

A- Area of the panel

Ps- Specific Power (Power per $\mathrm{m}^{2}$ )

$\eta$ - efficiency

T- Hours of charging per day

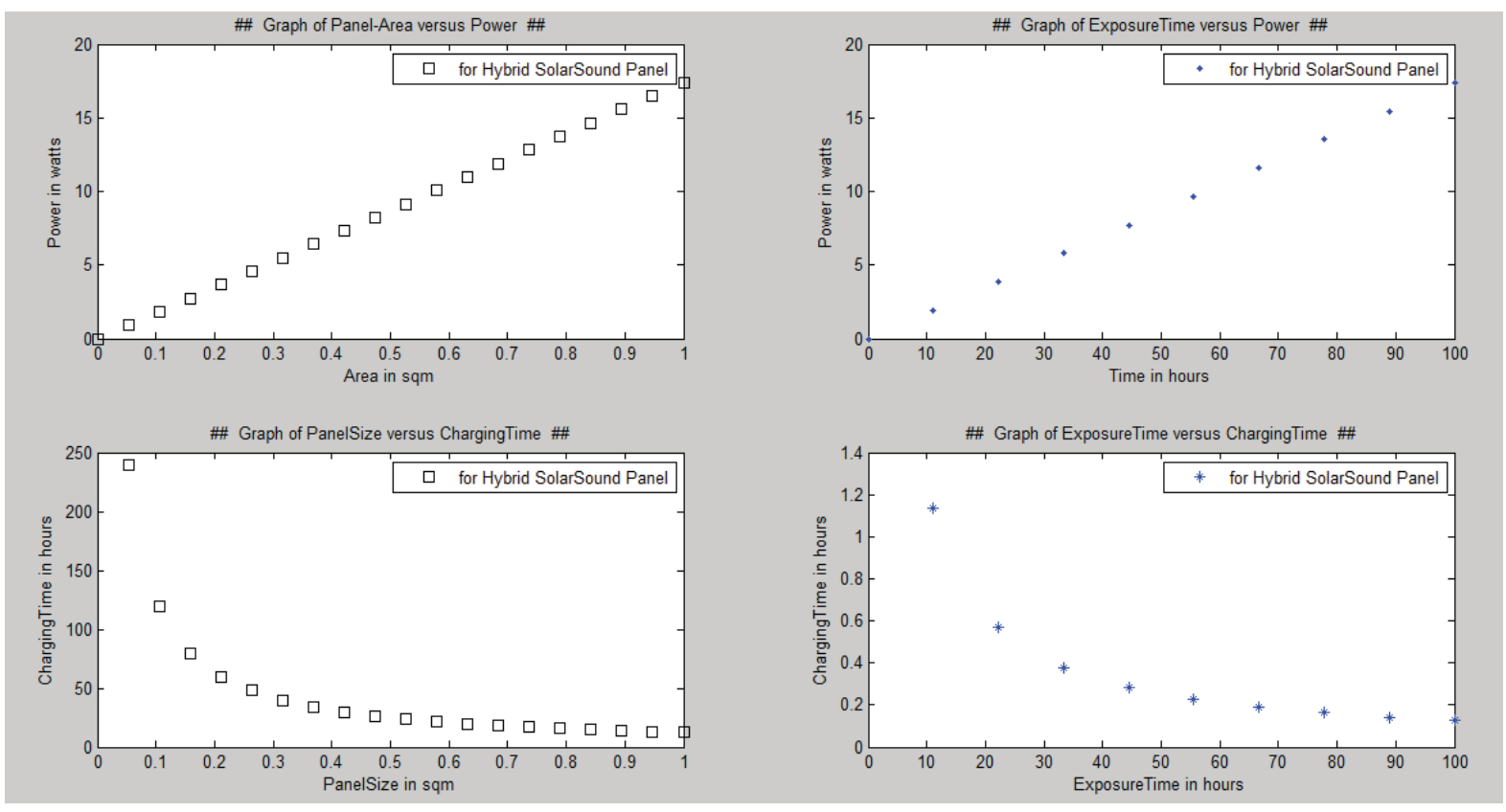

Fig 4: Matlab simulations 


\section{AdVANTAGES OF HYBRID SOUND-SOLAR PANEL}

1. The unwanted noise pollution can be converted into wanted electric energy.

2. By using these energy sources we can generate a energy continuously without depending on any other factors.

3. Pollution free environment and public health is safeguarded [4].

4. Easy for maintenance and maintenance cost is low.

\section{ApPLiCATIONS}

Conversion of sound energy into electric energy can be used in Aerospace. Hybrid sound-solar energy can be used in railway stations, Bus stand, Stadium, Highway, Clubs- pubs and Nuclear power stations.

\section{CONCLUSION AND FUTURE SCOPE}

Power generation with low cost and using non-conventional energy sources will help to conserve the conventional energy source to meet the future demand. In future efficiently conversion of sound energy into electric energy become one of the greatest renewable energy source like solar. Because sound is a natural source of energy which can't be avoided. Example in highway more vehicles travel in a day. the vibration produced by vehicle and the sound produced by horn these all are part of renewable energy source which not used. By implementing hybrid solar and sound panel continuous energy from sound and solar can be generated efficiently and in large amount.

\section{REFERENCES}

[1] Reena Garasangi, Vijaykumar Sajjanar, Mallikarjun "Novel Hybrid Solar Sound Panel for Conversion of Sound and Solar energy" IEEE publications, IOTA'2016, Pune,India

[2] Mohana Faroug Saeed Attia1, Afraa Ibraheim Mohmmed Abdalateef "Evaluation of Electric Energy Generation from Sound Energy Using Piezoelectric Actuator" International Journal of Science and Research (IJSR) (2013).

[3] http://in.mathworks.com/solutions/energy-production/solar-power.html

[4] Milad Abbasil et al., "Impact of wind turbine sound on general health, sleep disturbance and annoyance of workers: a pilot- study in Manjil wind farm, Iran”, Journal of Environmental Health Science \& Engineering (2015) 13:71 